\title{
PARENTAL AWARENESS OF ADOLESCENT SUBSTANCE USE
}

Robert J. Williams; University of Lethbridge

Dale R. McDermitt; Psychiatrist in Consultative Practise, Duncan, British Columbia

Lorne D. Bertrand; Canadian Research Institute for Law and the Family, University of Calgary

R. Meghan Davis; University of Calgary

published in Addictive Behaviors (2003), 28 (4), 803-809

\author{
Direct correspondence to: Dr. Robert Williams \\ School of Health Sciences \\ University of Lethbridge \\ Lethbridge, Alberta \\ CANADA; T1K 3M4 \\ robert.williams@uleth.ca
}




\begin{abstract}
Parental awareness of adolescent substance use was investigated in a high school sample of 985 adolescents and their parents. Only 39\% of parents were aware their adolescent used tobacco, only $34 \%$ were aware of alcohol use, and only $11 \%$ were aware of illicit drug use. There were no variables that differentiated aware from unaware parents for all substances. Greater parental awareness of alcohol and tobacco use occurred with older adolescents. High adolescent ratings of family communication combined with low parental ratings of family communication were also associated with greater parental awareness of alcohol and tobacco use. Better school grades predicted greater awareness of alcohol and illicit drug use. Single parents and blended families were more aware of tobacco and illicit drug use.
\end{abstract}

Key Words: adolescent, substance, awareness, parent, drug 
Introduction

Judgments about the presence or absence of child and adolescent psychopathology depend on whether the informant is the parent, child, peer, or teacher. A comprehensive summary of the literature by Achenbach, McConaughy, and Howell (1987) found that informants' reports about child/adolescent behavioural and emotional problems were significantly correlated with each other, but that the magnitude of the correlations was fairly low. Although an average Pearson correlation coefficient of .60 was obtained between informants having similar roles (e.g., mother versus father), the coefficients were only .28 between informants with different roles (e.g., parent versus teacher), and .22 between the child/adolescent's self-rating and other informants' ratings. One factor influencing inter-rater reliability is the type of problem, with somewhat less agreement on internalizing problems compared to more obvious externalizing problems (Achenbach, et al., 1987). A second factor is age, with somewhat less agreement occurring with older children (Achenbach et al., 1987). No significant differences have been found for mothers versus fathers, boys versus girls, or clinical versus nonclinical samples (Achenbach et al., 1987). Individual studies since Achenbach et al.'s (1987) review have largely confirmed these findings (e.g., Engel, Rodrigue, and Geffken, 1994; Hart, Lahey, Loeber, and Ranson, 1994; Kazdin, 1994; Sourander \& Piha, 1997; Stanger \& Lewis, 1993).

Relatively few studies have examined parent-adolescent agreement concerning reports of adolescent alcohol/drug use. Friedman, Glickman, and Morrissey (1990) found that mothers consistently reported a lower range and frequency of substance use than did their adolescents, but more problems associated with substance use. O'Donnell et al. (1998) also found parents reporting lower rates of substance use than did their adolescents. Agreement was highest for cigarette smoking, followed by alcohol abuse or dependence, followed by drug abuse or dependence. Cantwell et al. (1997) found fair parent-adolescent agreement on drug abuse/dependence, but poor agreement for alcohol abuse/dependence. A national survey conducted by the Partnership for a Drug Free America (CESAR, 1996) found child reports of drug/alcohol use to be considerably higher than parent reports. For example, 14\% of parents reported that their children had used marijuana at least once, whereas 38\% of the adolescents reported having done so. Finally, Deffenbaugh, Hutchinson, and Blankschen (1993) compared differences in the reported usage of drugs/alcohol of youth in rural Indiana compared to parents' perceptions of students' use. Here again, parents significantly underestimated the percentage of students in their child's grade who reported the use of a variety of substances, especially alcohol.

These results suggest that parents are fairly unaware of the extent of substance use amongst their children. The present study is a further investigation of this issue. The above studies have been limited either by small sample sizes (i.e., Friedman et al., 1990), low base rates of substance use (i.e., Cantwell et al., 1997), not directly matching the report of the adolescent to the report of their parent (i.e., CESAR, 1996; Deffenbaugh et al., 1993), or by obtaining adolescent self-report in a non-

anonymous fashion (i.e., Friedman et al., 1990; Cantwell et al., 1997; O'Donnell et al., 1998). Most of these studies have also examined substance abuse rather than substance use. The second purpose of the present study is to identify factors related to parental awareness. Knowledge of these factors would aid clinicians in their judgment of the veracity of parental report. These factors could also help shape educational strategies designed to increase parental and societal awareness of adolescent substance use.

Method

\section{Sampling Procedure}

This study is a secondary analysis of data collected in a provincial study of the prevalence of substance use among adolescents in Alberta, Canada (Bertrand, Smith, Bolitho \& Hornick, 1993). A total of 3,390 students ages 12 to 18 were randomly selected from 9 school districts throughout the province. Following student selection, a letter was mailed to their parents requesting their consent to have themselves and their child participate in a "Youth and Family Lifestyle Survey". A total of 2901 
families gave consent. A member of the research team distributed the Adolescent Questionnaire to students in their classrooms. Students were assured the information would remain confidential and anonymous and they could omit any questions they did not wish to answer. Completed questionnaires were obtained from 2,118. Gender was evenly split between males (51.5\%) and females (48.5\%). Age distribution closely approximated the age distribution of the Alberta high school student population. Parent Questionnaires were mailed to the households of the 2,901 students. A total of $1,388(47.8 \%)$ parents returned a completed questionnaire. Respondents were primarily female (79.8\%) and married (78.5\%). Thirty-two percent had completed college or university, which is very close to the typical educational attainment of adult Albertans (Statistics Canada, 1996). The only identifying information on the questionnaires was the school the adolescent attended, gender, and date of birth. Using this information, successful adolescent-parent matches were obtained for 985 of the 1,388 parent questionnaires.

\section{Questionnaires}

The Adolescent Questionnaire gathered information on age, gender, average grade, family functioning, social functioning, emotional health, behavioural functioning, and substance use. The questionnaire incorporated three established scales having good psychometric properties: A modification of the Child Behaviour Checklist as used in the Ontario Child Health Study (Boyle \& Offord, 1991) provided measures of emotional disturbance, conduct disorder, somatic complaints, and attentional problems. Self-esteem was assessed using the Rosenberg Self-Esteem Scale (Rosenberg, 1965). Family functioning/communication was measured using the General Functioning Subscale of the McMaster Family Assessment Device (Epstein, Baldwin, \& Bishop, 1983). Substance use was assessed with questions that asked the adolescent whether he/she had used a particular substance in the past month (cigarettes, alcohol, marijuana or hashish, glue or solvents, cocaine or crack, hallucinogens, barbiturates or tranquilizers without a prescription, amphetamines or stimulants without a prescription, or opiates). For each substance they had used, they were asked to indicate frequency of use on an 8-point scale ranging from once or twice to several times a day.

The Parent Questionnaire gathered information on the parent's age, gender, educational attainment, family functioning, and substance use. Parents were also asked questions pertaining to how much they participated in and monitored their adolescent's activities, and to what extent they imposed rules at home. The substance use questions asked whether they believed their teenager was currently using a particular substance (yes, no, unsure). They were also asked about their own current and past history of substance use.

Results

\section{Accuracy of Parental Judgment}

Table 1 reports the self-reported rates of substance use in the past month among adolescents, parental beliefs about their adolescent's substance use, and accuracy of parental beliefs. Because of the low frequency of reported use, substances other than alcohol and tobacco have been combined into "illicit drug use".

In the past month, 23\% (197/854) of adolescents reported using 1-5 cigarettes/day or more, $46 \%$ (390/854) reported using 1-2 alcoholic drinks or more, and 10.8\% (92/852) reported using an illicit drug. Considerably fewer parents believed their adolescent was using substances. Only $9.8 \%$ (84/854) believed their adolescent had smoked tobacco in the past month, only $18.3 \%(156 / 854)$ believed their adolescent had drank alcohol, and only 1.5\% (13/852) believed their adolescent had used illicit drugs.

A kappa statistic measured the overall degree of agreement between parent and adolescent, excluding all cases where the parent was uncertain. The degree of agreement for tobacco use was fairly good $(\kappa=.50, p<.0001,832$ pairs). Agreement was low for both alcohol use $(\kappa=.33, p<$ $.0001,812$ pairs), and illicit drug use $(\kappa=.20, p<.0001,823$ pairs $)$. In all three situations the main 
discrepancy was parents reporting their adolescent did not use a substance when the adolescent reported that they had.

\section{Variables Related to Parental Awareness of Adolescent Substance Use}

An SPSS forward stepwise logistic regression investigated characteristics differentiating parents who were aware their adolescent was using a substance from parents who were unaware. Variable entry order was determined by the size of the Wald statistic, with a minimum entry level of $p=$ .05 and a removal level of $p=.10$. A separate analysis was done for tobacco use, alcohol use, and illicit drug use. Twenty predictor variables were used in each analysis. Table 2 reports the significant variables in each of the 3 logistic regressions.

There were no variables that differentiated aware from unaware parents for all substances. Greater parental awareness of alcohol and tobacco use occurred with older adolescents. High adolescent ratings of family communication combined with low parental ratings of family communication were also associated with greater parental awareness of alcohol and tobacco use. Better school grades predicted greater awareness of alcohol and illicit drug use. Single parents and blended families were more aware of tobacco and illicit drug use.

\section{Discussion}

Only a minority of parents believed their adolescent used tobacco, alcohol or illicit drugs. This, combined with a low base rate of actual use, meant that parents were usually correct when reporting their adolescent did not use. However, parental accuracy was poor when adolescents did use substances. Only 39\% of parents were aware their adolescent smoked tobacco, only $34 \%$ were aware their adolescent drank alcohol, and only $11 \%$ were aware their adolescent used illicit drugs. Although parental unawareness of alcohol and illicit drug use has been previously reported, this is the first study to document this for substance use in a matched sample of parents and adolescents. This study's finding that parents are also unaware of adolescent tobacco use is something that has not been previously well researched or recognized.

Lack of awareness is a serious concern in light of the fact that parents have the potential of deterring drug usage in their children, as well as typically being the ones identifying the need for treatment and accessing services. An obvious implication of this study is that parents need to be more aware of the prevalence of substance use in youth and more alert to the signs and symptoms of possible use. A second implication for clinicians and researchers is that in most circumstances there should be greater reliance on the adolescent's report rather than the parent's report in assessing substance use.

There were no variables related to greater awareness for all substances, but there were a few variables related to awareness for 2 out of 3 substances. Greater parental awareness of alcohol and tobacco use occurred with older adolescents, likely because 17 and 18 year olds are less likely to hide their use (18 is the legal age in Alberta for use of these substances). Greater parental awareness of alcohol and tobacco use occurred when adolescents rated family communication as high, but when parents rated family communication as low. This may be because adolescents who are able to be open about their substance use perceive family communication/functioning to be good. In contrast, parents may perceive adolescent substance use as indicative of some failure in family communication/functioning. Alternatively, it may indicate that parents who believe that improvements need to be made in family communication/functioning are more vigilant of their adolescent's behaviour. Better school grades predicted greater awareness of alcohol and illicit drug use, suggesting either that adolescents' with good grades are less likely to hide their use or that alcohol use has a more noticeable impact on the academic achievement of good students. Single parents and blended families were more aware of tobacco and illicit drug use.

Several variables bore no relationship to increased parental awareness in any of the analyses. These were: adolescent gender, adolescent emotional disorder, self-esteem, adolescent hyperactivity, parental age, parental gender, parental level of education, parental tobacco use, and parental monitoring and imposition of rules. The failure of this last variable could be because parents 
are poor judges of how well they monitor their adolescent's behaviour or because parental monitoring and imposition of rules may in some cases be due to concerns about what their son/daughter is involved in. 


\section{References}

Achenbach, T.M., McConaughy, S.H., Howell, C.T. (1987). Child/Adolescent behavioral and emotional problems: Implications of cross-informant correlations for situational specificity. Psychological Bulletin, 101, 213-232.

Bertrand, L.D., Smith, R.B., Bolitho, F.H., Hornick, J.P. (1993). Substance use among Alberta adolescents: Prevalence and related factors. Edmonton, Alberta: Premier's Council in Support of Alberta Families and Canadian Research Institute for Law and the Family.

Boyle, M.H., Offord, D.R. (1991). Psychiatric disorder and substance use in adolescence. Canadian Journal of Psychiatry, 36, 699-705.

Cantwell, D.P., Lewinsohn, P.M., Rohde, P., Seeley, J.R. (1997). Correspondence between adolescent report and parent report of psychiatric diagnostic data. Journal of the American Academy of Child \& Adolescent Psychiatry, 36, 610-619.

CESAR (1996). Poll shows that parents seriously underestimate availability and use of drugs among their children. In Partnership for a Drug Free America, Vol 5, Issue 16, April 29, 1996. University of Maryland at College Park.

Deffenbaugh, K.B., Hutchinson, R.L., Blankschen, M.P. (1993). Substance use among youth (Grades 4-12) in rural Indiana: Students' reported use versus parents' perceptions of students' use. Journal of Alcohol and Drug Education, 39, 19-33.

Engel, N.A., Rodrigue, J.R., Geffken, G.R. (1994). Parent/child agreement on ratings of anxiety in children. Psychological Reports, 75, 1251-1260.

Epkins, C.C. (1996). Parent ratings of children's depression, anxiety, and aggression: A crosssample analysis of agreement and differences with child and teacher ratings. Journal of Clinical Psychology, 52, 599-608.

Epstein, N.B., Baldwin, L.M., Bishop, D.S. (1983). The McMaster Family Assessment Device. Journal of Marital and Family Therapy, 9, 171-180.

Friedman, A.S., Glickman, N.W., Morrissey, M.R. (1990). What mothers know about their adolescents' alcohol/drug use and problems, and how mothers react to finding out about it. In A.S. Friedman \& S. Granick, (eds.), Family Therapy for Adolescent Drug Abuse (pp 169-181). Lexington: Lexington Books.

Hart, E.L., Lahey, B.B., Loeber, R., Ranson, K.S. (1994). Criterion validity of informants in the diagnosis of disruptive behavior disorders in children: A preliminary study. Journal of Consulting and Clinical Psychology, 62, 410-414.

Kazdin, A.E. (1994). Informant variability in the assessment of childhood depression. In W.M. Reynolds, H.F. Johnston, et al., (eds.), Handbook of Depression in Children and Adolescents: Issues in Clinical Child Psychology (pp 249-271). New York, NY: Plenum.

O’Donnell, D., Biederman, J., Jones, J., Wilens, T.E., Milberger, S., Mich, E., Faraone, S.V. (1998). Informativeness of child and parent reports on substance use disorders in a sample of ADHD probands, control probands, and their siblings. Journal of the American Academy of Child \& Adolescent Psychiatry, 37, 752-758.

PRIDE (1998). Teen drug use remains at all time high: Too few parents talk to their children about drugs. May 14, 1998 Press Release concerning PRIDE's Canadian National Survey of Adolescent Drug Use. Saskatoon, Saskatchewan: Parent Resources Institute for Drug Education. Press.

Rosenberg, M. (1965). Society and the Adolescent Self-Image. Princeton: Princeton University

Sourander, A., Piha, J. (1997). Parent, teacher and clinical ratings on admission to child psychiatric inpatient treatment: A study of cross-informant correlations using the CBCL, Rutter scales and the CGAS. Nordic Journal of Psychiatry, 51, 365-370.

Stanger, C., Lewis, M. (1993). Agreement among parents, teachers, and children on internalizing and externalizing behavior problems. Journal of Clinical Child Psychology, 22, 107-115.

Statistics Canada (1996). Population 15 years and over by highest degree, certificate or diploma, 1996 Census. Ottawa, Ontario: Government of Canada. 
Thomas, A.M., Forehand, R., Armistead, L., Wierson, M., et al., (1990). Cross-informant consistency in externalizing and internalizing problems in early adolescence. Journal of Psychopathology \& Behavioral Assessment, 12, 255-262. 
Table 1

Accuracy of Parental Beliefs about their Adolescent's Substance Use

Tobacco

$A+A-$

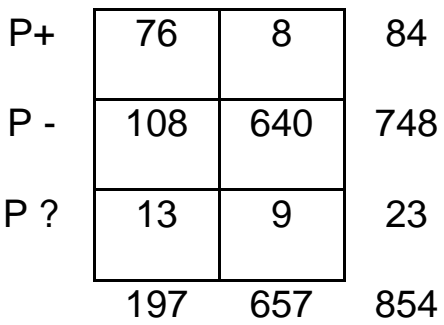

$\kappa=.50$
Alcohol

$A+A-$

\begin{tabular}{|c|c|c|}
\hline $\mathrm{P}+$ & 133 & 23 \\
\hline P - & 231 & 425 \\
\hline & 26 & 16 \\
\hline & 390 & 464 \\
\hline
\end{tabular}

$\kappa=.33$
Illicit Drugs

$A+A-$



$\kappa=.20$

A+ adolescent reports using in the past month (at least 1-5 cigarettes/day for

tobacco; 1-2 times in month for alcohol or illicit drugs)

A - adolescent reports no use in past month

$\mathrm{P}+\quad$ parent believes their teen has used in the past month

P - parent believes their teen has not used in the past month

P ? $\quad$ parent unsure whether their teen has used in the past month 
Table 2

Variables Related to Parental Awareness that their Adolescent is Using Substances

\begin{tabular}{rccc} 
& Tobacco & Alcohol & Illicit Drugs \\
\hline adolescent age & $.10^{\star}$ & $.34^{\star \star \star}$ & -.15 \\
adolescent gender & 0 & 0 & 0 \\
family composition & $.15^{\star \star}$ & 0 & $.22^{\star}$ \\
conduct disorder & 0 & 0 & $.20^{\star}$ \\
emotional disorder & 0 & -.02 & 0 \\
hyperactivity disorder & 0 & 0 & 0 \\
somatic symptoms & 0 & $.14^{\star \star \star}$ & 0 \\
self-esteem & -.06 & 0 & -.15 \\
family communication/functioning & $.12^{\star}$ & $.11^{\star \star}$ & 0 \\
frequency of substance use & $.34^{\star \star \star}$ & 0 & 0 \\
parent gender & 0 & 0 & 0 \\
level of education of parent & 0 & 0 & 0 \\
child's average grade & -.06 & $.17^{\star \star *}$ & $.28^{\star \star}$ \\
family communication/functioning & $-.22^{\star \star \star}$ & $-.09^{\star *}$ & 0 \\
participation in adolescent's activities & 0 & .06 & $-.28^{\star}$ \\
parental monitoring and rule imposition & 0 & -.05 & 0 \\
parental tobacco use & -.01 & 0 & 0 \\
parental alcohol use & 0 & $.10^{\star \star}$ & 0 \\
parental marijuana use & -.02 & $.10^{\star \star}$ & 0 \\
\hline
\end{tabular}

$* p<.05 \quad * \star p<.01 \quad * \star * p<.001$

Note. The top set of variables are from the adolescent questionnaire and the bottom set are from the parent questionnaire. Values reported are regression coefficients from the logistic regression analyses. 